\title{
Risk factors and mechanisms of hepatocarcinogenesis with special emphasis on alcohol and oxidative stress
}

\author{
Helmut K. Seitz ${ }^{1, *}$ and Felix Stickel ${ }^{2}$ \\ ${ }^{1}$ Department of Medicine and Laboratory of Alcohol \\ Research, Liver Disease and Nutrition, Salem Medical \\ Center, D-69121 Heidelberg, Germany \\ ${ }^{2}$ Institute of Clinical Pharmacology, University of Berne, \\ $\mathrm{CH}-3010$ Berne, Switzerland \\ ${ }^{*}$ Corresponding author \\ e-mail: helmut_karl.seitz@urz.uni-heidelberg.de
}

\begin{abstract}
Hepatocellular cancer is the fifth most frequent cancer in men and the eighth in women worldwide. Established risk factors are chronic hepatitis B and C infection, chronic heavy alcohol consumption, obesity and type 2 diabetes, tobacco use, use of oral contraceptives, and aflatoxin-contaminated food. Almost $90 \%$ of all hepatocellular carcinomas develop in cirrhotic livers. In Western countries, attributable risks are highest for cirrhosis due to chronic alcohol abuse and viral hepatitis B and C infection. Among those with alcoholic cirrhosis, the annual incidence of hepatocellular cancer is 1-2\%. An important mechanism implicated in alcohol-related hepatocarcinogenesis is oxidative stress from alcohol metabolism, inflammation, and increased iron storage. Ethanolinduced cytochrome P-450 2E1 produces various reactive oxygen species, leading to the formation of lipid peroxides such as 4-hydroxy-nonenal. Furthermore, alcohol impairs the antioxidant defense system, resulting in mitochondrial damage and apoptosis. Chronic alcohol exposure elicits hepatocyte hyperregeneration due to the activation of survival factors and interference with retinoid metabolism. Direct DNA damage results from acetaldehyde, which can bind to DNA, inhibit DNA repair systems, and lead to the formation of carcinogenic exocyclic DNA etheno adducts. Finally, chronic alcohol abuse interferes with methyl group transfer and may thereby alter gene expression.
\end{abstract}

Keywords: acetaldehyde; cytochrome P4502E1; hepatitis; methyl group transfer; reactive oxygen species; retinoids.

\section{Introduction}

Recent epidemiological data (from the year 2000) indicate that more than 560000 new cases of hepatocellular cancer (HCC) occurred worldwide, which accounted for $5.6 \%$ of all human cancers (Bosch et al., 2004). Thus, $\mathrm{HCC}$ is the fifth most common malignancy in men and the eighth in women. Age-adjusted incidence rates for HCC were found to be extremely high in East and Southeast Asia, and in Africa (Ferlay et al., 2001). In Europe, there is a gradually decreasing prevalence from South to North. Overall, incidence rates for HCC were found to be higher in males compared to females. The worldwide $\mathrm{HCC}$ incidence rate doubled during the last two decades and younger age groups are increasingly affected (ElSerag and Mason, 2000; El-Serag, 2004). Risk factors for $\mathrm{HCC}$ may explain the high prevalence in Asia and Africa because of widespread infection with hepatitis $B(\mathrm{HBV})$ and hepatitis $\mathrm{C}$ virus (HCV). It is estimated that at least $75-80 \%$ of cases of primary HCC are attributable to chronic viral hepatitis (Bosch et al., 1999). In addition, other risk factors include chronic alcohol misuse, nonalcoholic fatty liver disease (NAFLD), tobacco, oral contraceptives, and food contamination with aflatoxins. In Europe and in the United States, estimates of attributable risk are highest for chronic alcohol consumption, followed by HCV and HBV infections (Donato et al., 2002; Hassan et al., 2002). A major prerequisite for HCC is established liver cirrhosis, as reflected by the observation that $80-90 \%$ of all HCC develops in cirrhotic livers. Up to $54-70 \%$ of patients with compensated cirrhosis due to different etiologies and $50 \%$ of those with cirrhosis due to chronic hepatitis $\mathrm{C}$ die from HCC (Fattovich et al., 2004). The increase in HCC may also reflect better therapeutic management of cirrhosis, resulting in longer survival and allowing the development of HCC. The 5-year cumulative HCC incidence in cirrhosis is between $10 \%$ and $30 \%$ in HBV and HCV infection, depending on the geographic region, approximately $20 \%$ in hereditary hemochromatosis and $8 \%$ in alcoholic cirrhosis (Fattovich et al., 2004). Predictors of HCC in cirrhosis include the severity of liver disease determined by the ChildPugh score (Bolondi et al., 2001), the disease activity, reflected by serum transaminase activities (Benvegnu et al., 1994; Tarao et al., 1999), and some histological criteria, such as the presence of large cell changes (LCC) (Borzio et al., 1995; Ganne-Carrié et al., 1996), macronodules (Borzio et al., 2003) and markers for hyperregeneration (Donato et al., 2001; Trerè et al., 2003).

However, some HCCs may occur in non-cirrhotic livers of patients with HBV and HCV infection and chronic inflammation of the liver associated with increased fibrogenesis and hyperproliferation. However, chronic inflammation is associated with oxidative stress, which plays a major pathogenic role in most chronic liver diseases. As for chronic hepatitis C, structural and non-structural viral epitopes, such as the core protein or the NS5A protein, were shown to elevate oxidative pressure (Liang and Heller, 2004). 
In addition, patients with HBV infection show increased excretion of etheno DNA adducts in their urine, which results from the reaction of 4-hydroxynonenal (4-HNE) with DNA bases (Bartsch and Nair, 2004). This increase in etheno DNA adducts may arise from HBV-induced chronic inflammation and overproduction of reactive oxygen (ROS) and nitrogen species (RNS) and lipid peroxidation products. It is interesting that oxidative stress leading to lipid peroxidation and end products such as $4-\mathrm{HNE}$ results in mutation of the p53 gene at codon 249, which is a hot spot in $\mathrm{HCC}(\mathrm{Hu}$ et al., 2002). A strong synergistic effect exists between HBV infection and aflatoxin B1 exposure on incidence rates of $\mathrm{HCC}$ and on the mutation of the p53 gene at codon 249 (Smela et al., 2002). Although in cultured hepatocytes aflatoxin B1 binds at other codons than 249 of the $p 53$ gene (Denissenko et al., 1998; Hu et al., 2002), it is possible that HBV infection and aflatoxin B1 exposure could result in enhanced lipid peroxidation, and lipid peroxidation products such as 4-HNE generated by HBV infection and aflatoxin B1 exposure may damage codon 249 of the p53 gene, initiating carcinogenesis (Ross et al., 1992; Smela et al., 2002). Thus, oxidative stress does occur in viral hepatitis, but may be potentiated by concomitant aflatoxin B1 exposure, which has been found in certain geographic areas of Africa and Asia.

It is beyond the scope of this review to discuss all risk factors for HCC with respect to oxidative stress and readers are referred to detailed reviews devoted to this issue (Bréchot, 2004; Fattovich et al., 2004; Kowdley, 2004; Liang and Heller, 2004; Yu and Yuan, 2004). The present review focuses on alcohol-related HCC, with special emphasis on oxidative stress. Other alcohol-related mechanisms promoting the development of $\mathrm{HCC}$ are outlined elsewhere (Stickel et al., 2002; Pöschl and Seitz, 2004; Stickel and Seitz, 2004; McKillop and Schrum, 2005).

\section{Epidemiology of alcohol and hepatocellular cancer}

Alcohol use is common in the U.S. and Western Europe and is increasing in Asia. In the U.S., $7 \%$ of the adult population meet the definition for alcohol misuse or dependence, thereby exceeding the prevalence of hepatitis C by five-fold (Grant et al., 1994). Similar data exist for some countries in Europe, including Germany, where 1.5 million individuals are alcohol-dependent and approximately 3 million people have alcohol-associated organ damage (Deutsche Hauptstelle für Suchtfragen, 2003). Case-control studies in countries with a high prevalence of alcohol use and a moderate prevalence of viral hepatitis, as well as studies from countries with a high prevalence of chronic viral hepatitis and a lower prevalence of alcohol use, report that chronic ethanol consumption is associated with an approximately two-fold increased risk for HCC (Morgan et al., 2004). The odd ratios increase further to five- to seven-fold when ethanol use exceeds $80 \mathrm{~g} /$ day for more than 10 years (Tagger et al., 1999; Hassan et al., 2002). In general, patients with alcoholic liver cirrhosis show HCC incidence of $1-2 \%$.
Although alcohol itself leads to liver cirrhosis and promotes HCC, it is also a co-factor for the development of HCC in other chronic liver diseases. Thus, chronic alcohol misuse may enhance and/or accelerate hepatocarcinogenesis in patients with HBV and HCV infection, with hereditary hemochromatosis, or with NAFLD. With respect to viral hepatitis, alcohol may stimulate oxidative stress and may, therefore, contribute to inflammation (see below). It has been shown that chronic alcohol consumption of more than $25 \mathrm{~g} /$ day leads to a 10 -year earlier occurrence of HCC in a Japanese population (Ohnishi, 1992) indicating an accelerating effect of alcohol in HBVdriven hepatocarcinogenesis. Chronic alcohol misuse also increases the risk of HCV infection (Inoué and Seitz, 2001). Whether this is due to impaired function of the immune system following alcohol ingestion or relates to the risky lifestyle of alcoholics is still unknown. In addition, alcohol may increase viral replication, possibly by immunosuppression. Finally, alcohol may stimulate inflammation and, thus, oxidative stress (Morgan et al., 2004).

In hereditary hemochromatosis, hepatic iron overload is a major factor in hepatocarcinogenesis (Kowdley, 2004) and alcohol enhances iron deposition in the liver, resulting in increased oxidative stress (see below).

With respect to NAFLD, it has become clear that type 2 diabetics are at increased risk for HCC (El-Serag, 2004). The pathogenesis of NAFLD includes the accumulation of fat in the liver, which may be predominantly induced by hyperinsulinemia due to peripheral insulin resistance. Free fatty acids induce cytochrome P4502E1 (CYP2E1) and lead to ROS (Neuschwander-Tetri and Caldwell, 2003). Alcohol also increases CYP2E1 and enhances this pathophysiological pathway. In addition, tumor necrosis factor $\alpha$ (TNF $\alpha)$ is elevated in NAFLD and alcoholic liver disease (ALD), resulting in further aggravation of peripheral insulin resistance and in oxidative stress. It has been shown that the relative risk for HCC in type 2 diabetics is approximately 4 , and it increases to almost 10 for consumption of more than $80 \mathrm{~g}$ alcohol per day (Hassan et al., 2002).

\section{Mechanisms of alcohol-associated carcinogenesis}

Despite the substantial epidemiological data in humans that chronic alcohol ingestion causes cirrhosis and HCC, the mechanisms of the pathogenesis are still not completely understood. Alcohol by itself is not a carcinogen when given to animals (Ketcham et al., 1963). However, alcohol enhances chemically induced hepatocarcinogenesis, especially when nitrosamines are used for tumor induction (Pöschl and Seitz, 2004). Thus, under certain experimental conditions, alcohol may act as a tumor promoter.

It should be pointed out that $30-50 \%$ of individuals with HCC show a loss of heterozygosity of the long arm of chromosome 4 (Laurent-Puig et al., 2001). In French patients with HCC, a loss of 4Q34-3 in particular was reported (Bluteau et al., 2002). However, a large proportion of these patients were infected with HCV. 


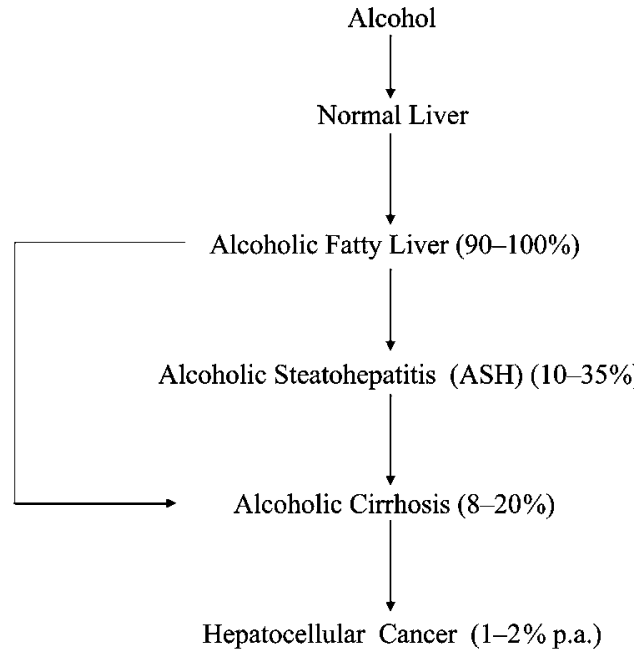

Figure 1 Development of alcoholic liver disease following chronic heavy alcohol abuse.

p.a., per annum.

Various mechanisms may contribute to alcohol-associated carcinogenesis, including: (1) chronic inflammation resulting in increased oxidative stress, such as in alcoholic steatohepatitis (ASH); (2) acetaldehyde and its detrimental effect on proteins and DNA; (3) induction of CYP2E1 leading to increased ROS production, lipid peroxidation and DNA damage; (4) a decrease in antioxidant defense and DNA repair; (5) disturbed methyl transfer associated with DNA hypomethylation; (6) decreased hepatic retinoic acid (RA); (7) iron overload; and (8) profound impairment of the immune system.

\section{Alcohol and inflammation}

When alcohol consumption is regularly above a certain threshold, fatty liver develops in almost $100 \%$ of cases. However, only $30 \%$ of these patients develop alcoholic fibrosis either with or without inflammation, and only 10-20\% progress to liver cirrhosis (Becker et al., 1996) (Figure 1). It has been speculated that genetic aspects may play a predominant role, explaining why not every alcoholic develops advanced liver disease. Although polymorphisms of genes involved in ALD have been intensively studied, the results so far are disappointing (Stickel and Österreicher, 2006). HCC almost always occurs in alcoholic cirrhosis. Recently it has been shown that some histological phenotypes of hepatocytes, observed in experimental alcoholic hepatitis long before cancer develops, may act as an early predictive marker for HCC development. Thus, in a mouse model the Mallory body-forming cell phenotype induced by diethyldithiocarbamate seemed to be preneoplastic in nature (French et al., 2005).

The mechanism in the pathogenesis of ASH includes the uptake of intestinal endotoxins from the gut to the liver via the portal vein. These endotoxins (lipopolysaccharides) bind to the CD14/toll 4 receptor complex of Kupffer cells in the liver, leading to intracellular signal transduction, with the release of proinflammatory cytokines, particularly TNF- $\alpha$, eicosanoids, ROS and nitric oxide (NO) (Jarvelainen et al., 1999; Hines and Wheeler,
2004). It has been shown in animal experiments that both the administration of antibiotics to reduce endotoxemia and the inactivation of Kupffer cells with gadolinium chloride prevent liver injury (Thurman, 1998). CD 14 or CD 14-coupled toll like receptor 4 knockout mice with less TNF- $\alpha$ production are also resistant to alcohol toxicity (Uesugi et al., 2001; Yin et al., 2001). Furthermore, inhibition of TNF- $\alpha$ by TNF- $\alpha$ antibodies or by the use of a TNF- $\alpha$ receptor knockout mouse model also protects against alcohol-induced liver injury (Hines and Wheeler, 2004). TNF- $\alpha$ results - after binding to its receptor (TNF $\alpha-R 1)$ - in cell apoptosis. However, hepatocytes are resistant to the proapoptotic effects of binding to its receptor in cell proliferation, necrosis, or apoptosis, depending on the TNF- $\alpha$, owing to the concomitant induction of antiapoptotic signals such as NF-кB (Wajant et al., 2003). TNF- $\alpha$ also induces OS, which in turn enhances TNF- $\alpha$ toxicity. The mechanism is not yet fully understood.

Figure 2 shows a simplified scheme of the pathogenesis of ASH. Besides other factors, interleukin 6 (IL-6) is significantly elevated in alcoholic patients with advanced liver disease (Urbaschek et al., 2001). It has to be pointed out that IL-6 inhibits hOGG1, an important repair enzyme for 8-oxo-guanosine adducts (Bartsch and Nair, 2004). IL-6 is also antiapoptotic through upregulation of the antiapoptotic gene $\mathrm{mcl}-1$ (Lin et al., 2001). Both factors favor carcinogenesis (Figure 3).

Liver cirrhosis may develop from ASH. However, it is not clear whether ASH with its enormous inflammationdriven oxidative stress and hyperproliferation is an important prerequisite for cancer development some decades later in the state of cirrhosis. Therefore, it would be important to know whether cirrhotic patients who went through $\mathrm{ASH}$ have an increased risk for HCC compared to those without ASH.

\section{Ethanol metabolism and hepatocarcinogenesis}

Figure 4 illustrates ethanol metabolism and its interference with metabolic pathways important in hepatocarcinogenesis.

Acetaldehyde The first and major metabolite of ethanol oxidation is acetaldehyde. There is increasing evidence that acetaldehyde rather than alcohol itself is responsible for the cocarcinogenic effect of alcohol (Pöschl and Seitz, 2004). Acetaldehyde is highly toxic, mutagenic and carcinogenic. It interferes at many sites with DNA synthesis and repair, and may, consequently, result in tumor development (IARC, 1999). Numerous in vitro and in vivo experiments in prokaryotic and eukaryotic cell cultures, as well as in animal models, have shown that acetaldehyde has direct mutagenic and carcinogenic effects. It causes point mutations in the hypoxanthineguanine-phosphorybosyl transferase locus in human lymphocytes, and induces sister chromatide exchanges and gross chromosomal aberration (Obe et al., 1986; Dellarco, 1988; Helander and Lindahl-Kiessling, 1991). It induces inflammation and metaplasia of tracheal epithelium, delays cell cycle progression and enhances cell injury associated with hyperregeneration (Simanowski et al., 1994; Seitz et al., 2001). Acetaldehyde binds to 


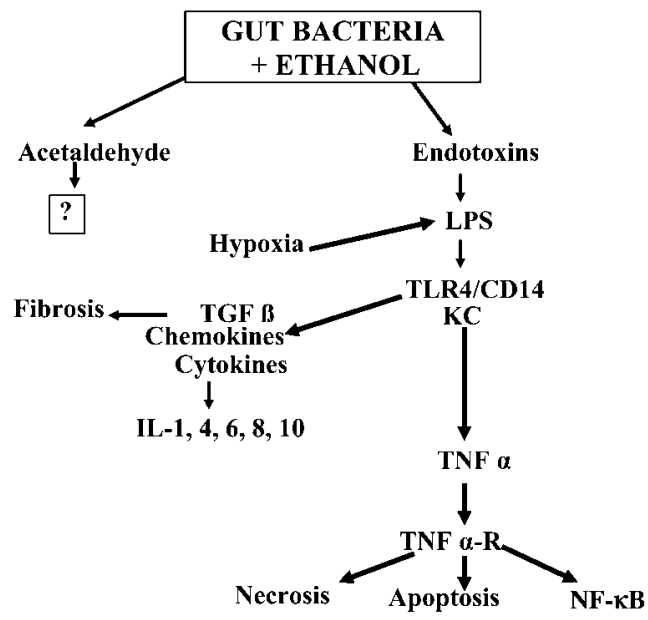

Figure 2 Simplified pathogenesis of alcoholic hepatitis. Bacterial endotoxins are translocated from the leaky gut to the portal vein and are delivered to the liver, where they bind to tolllike receptors (TLR) and CD14 receptors of Kupffer cells (KC). As a result, chemokines and cytokines (interleukins 1, 4, 6, 8, 10) are released, including TGF- $\beta$ and TGF- $\alpha$. TGF- $\alpha$ binds to its receptor, leading to necrosis, apoptosis and activation of NF$\kappa \mathrm{B}$, among other effects.

proteins, resulting in structural and functional alterations, and decreases antioxidative defense systems by binding to glutathione, thus increasing oxidative stress indirectly. Acetaldehyde also injures microtubules and mitochondria. Decreased microtubular function leads to inhibition of the secretion of macromolecules such as very-lowdensity lipoproteins from the liver. Decreased mitochondrial function results in inhibition of fatty acid oxidation and ATP formation. Both factors favor the occurrence of

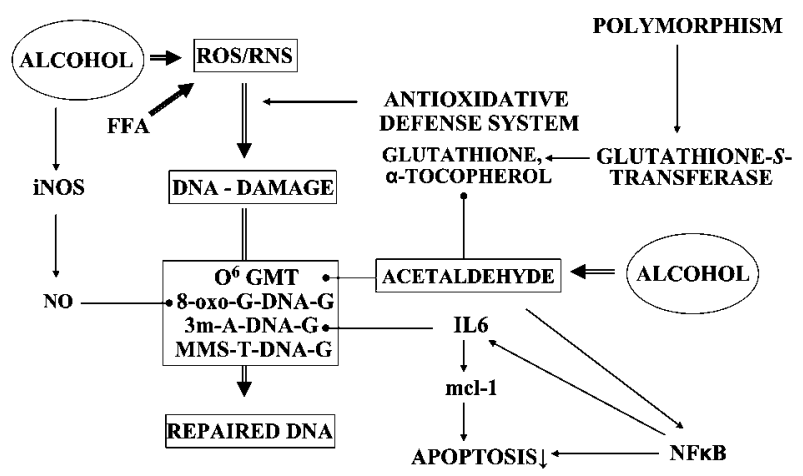

Figure 3 Effect of ethanol and acetaldehyde on DNA damage and repair.

Alcohol and free fatty acids induce cytochrome P-4502E1 and lead to the generation of reactive oxygen species (ROS) and reactive nitrogen species (RNS), which can be neutralized by the antioxidative defense system. Since this system is overloaded by an increased burden of ROS/RNS and due to inhibition by acetaldehyde, DNA damage may occur. Adequate DNA repair does not take place, since acetaldehyde, as well as nitric oxide (NO) produced by inducible nitric-oxide synthase (iNOS), inhibits the DNA repair systems. In addition, interleukin 6 (IL-6) released in alcoholic hepatitis and induced by NF-KB also inhibit DNA repair and apoptosis.

$\mathrm{O}^{6}$-GMT, $\mathrm{O}^{6}$ guanine-methyltransferase; 8-oxo-G-DNA-G, 8oxo-guanine-DNA glycosylase; 3M-A-DNA-G, 3-methyladenineDNA-glycosylase; MMS-T-DNA-G, mismatch-specific thymidine-DNA glycosylase. fatty liver (Lieber, 1994). In addition, mitochondrial damage induces apoptosis, but also survival factors such as NF-kB.

It has also been shown that acetaldehyde interferes with the DNA repair machinery. Acetaldehyde directly inhibits $\mathrm{O}^{6}$-methylguanosyl transferase, an enzyme important for the repair of DNA adducts (Espina et al., 1988). In the liver, acetaldehyde forms adducts with intracellular proteins and DNA, resulting in morphological and functional impairment of the cell, and a humoral immune reaction towards de novo generated antigens. Binding to DNA and the formation of stable adducts represents one mechanism by which acetaldehyde could trigger the occurrence of replication errors and/or mutations in oncogenes or tumor suppressor genes. The occurrence of stable DNA adducts has been shown in different organs of alcohol-fed rodents and in leukocytes of alcoholics (Fang and Vaca, 1997). It has been shown that the major stable DNA adduct $N^{2}$-ethyl desoxyguanosine (N2Et-dG) indeed serves as a substrate of eukaryotic DNA polymerase (Matsuda et al., 1999). More recently, another DNA adduct of acetaldehyde namely $1, N^{2}$-propano-desoxyguanosine (PdG) has been identified (Brooks and Theruvathu, 2005). Its generation occurs in the presence of basic amino acids, histones and polyamines. While N2-Et-dG is non-mutagenic and may be used as a marker for chronic alcohol ingestion, PdG has mutagenic properties. The action of acetaldehyde on DNA metabolism is summarized in Figure 3. According to the Agency for Research on Cancer, there is sufficient evidence to classify acetaldehyde as a carcinogen in experimental animals (IARC, 1999).

Recent and striking evidence of the causal role of acetaldehyde in ethanol-associated carcinogenesis was identified in genetic linkage studies in alcoholics. Individuals who accumulate acetaldehyde due to polymorphism and/or mutations in the gene coding for enzymes responsible for acetaldehyde generation and detoxification have been shown to have an increased cancer risk (Yokoyama et al., 1998). In this context it is interesting that in Caucasians polymorphism of alcohol dehydrogenase $1 \mathrm{C}$ $(A D H 1 C)$ exists and that the allele $A D H 1 C^{*} 1$ encodes for an enzyme with a high capacity to generate acetaldehyde. We recently identified the genotype $A D H 1 C^{*} 1 / 1$ as an independent risk factor for the development of alcohol-associated HCC among heavy drinkers, indicating a genetic predisposition of individuals carrying this genotype (Homann et al., 2006).

Cytochrome P-4502E1 and ROS generation Several enzymatic systems, including the CYP2E1-dependent microsomal mono-oxygenase system, the mitochondrial respiratory chain and the cytosolic enzymes xanthine oxidase and aldehyde oxidase, have been implicated as sources of $\mathrm{O}_{2}^{-}$and $\mathrm{H}_{2} \mathrm{O}_{2}$ in hepatocytes during ethanol oxidation (Albano, 2002). Alcohol-mediated free radical formation may be due to enhanced electron leakage from the mitochondrial respiratory chain, along with stimulation of NADH shuttling into mitochondria (Bailey and Cunningham, 2002), to an interaction between $N$-acetylsphingosine (from TNF- $\alpha$ ) and mitochondria (GarciaRuiz et al., 2000), to activated phagocytes in the liver 


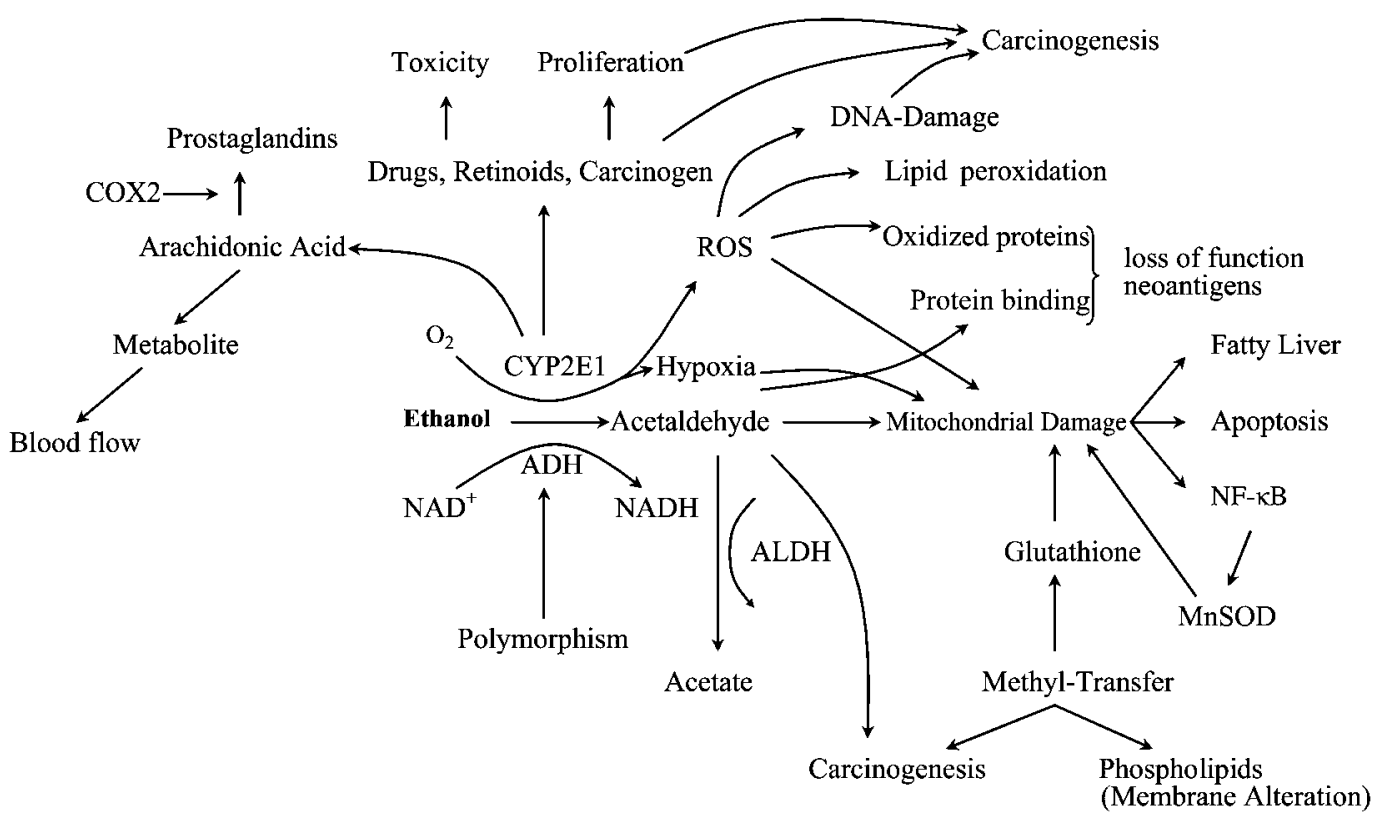

Figure 4 Ethanol metabolism and its role in alcoholic liver disease and carcinogenesis.

Ethanol is metabolized by alcohol dehydrogenases (ADHs), which reveal polymorphisms, and by cytochrome P-4502E1, which is inducible by chronic alcohol ingestion. The product acetaldehyde can be further metabolized by acetaldehyde dehydrogenase (ALDH). Acetaldehyde binds to proteins, forming neoantigens, and to DNA, forming DNA adducts. It damages mitochondria, with loss of function. As a result, fatty liver develops. Mitochondrial damage also initiates apoptosis and activation of the nuclear survival factor NF-кB. Alcohol-induced alterations in methyl-group transfer lead to DNA hypomethylation and membrane alterations. CYP2E1 also produces reactive oxygen species (ROS), which lead to lipid peroxidation, protein oxidation and DNA adducts. It also metabolizes drugs, activates various procarcinogens, and decreases retinol and retinoic acid.

COX2, cyclo-oxygenase 2; MnSOD, Mn-superoxide dismutase; NAD, nicotine adenine dinucleotide.

(Bautista, 2002), to hepatic iron overload (see below), and to nitric oxide (NO) (Chamulitrat and Spitzer, 1996). The reaction of $\mathrm{NO}$ with $\mathrm{O}_{2}^{-}$results in the formation of peroxynitrite (ONOO-), which is highly reactive and impairs cell function (Beckman and Koppenol, 1996). Inducible nitric oxide synthase (iNOS) is stimulated by ethanol and iNOS knockout mice are protected against alcohol-induced liver injury (Arteel, 2003). Although all these factors may contribute to the generation of ROS following alcohol ingestion, animal experiments have convincingly demonstrated the important role of CYP2E1 in the production of ROS and ALD.

Chronic alcohol consumption leads to a 10-20-fold induction of CYP2E1, which metabolizes ethanol to acetaldehyde. This cytochrome is also involved in the activation of various cocarcinogens to their ultimate carcinogens, including nitrosamines, aflatoxins, and polycyclic hydrocarbons. The interaction between ethanol and procarcinogen metabolism is complex and may depend on, among other factors, the degree of CYP2E1 induction, the chemical structure of the procarcinogen, and the presence or absence of ethanol in the body during procarcinogen metabolism. The events in this setting are reviewed elsewhere (Seitz and Osswald, 1992).

It has been shown that the concentration of CYP2E1 in the liver is correlated with the generation of hydroxyethyl radicals (HERs) and thus with lipid peroxidation (Dupont et al., 1998). HERs bind to proteins and form neoantigens (Albano et al., 1993). Antibodies against HER-derived epitopes are detectable in the sera of patients with ALD (Clot et al., 1995, 1996). Induction of
CYP2E1 resulted in ALD in animals, and inhibition of CYP2E1 was associated with an improvement in the damage (Gouillon et al., 2000). It has been concluded that this is mainly due to the stimulation and inhibition, respectively, of free radical formation. The role of CYP2E1 induction and cell injury has been studied in detail in the liver. For example, oxidized DNA products have been found to be lower in CYP2E1 knockout mice compared to wild-type mice (Bardag-Gorce et al., 2000; Bradford et al., 2005), whereas more pronounced hepatic damage was observed in transgenic mice overexpressing CYP2E1 (Morgan et al., 2002).

Although NADPH oxidase knockout mice do not produce a radical detectable by spin trapping, oxidative DNA damage does occur in these animals. Moreover, since CYP2E1 knockout mice reveal less DNA damage, at least two sources of oxidants may have additive effects on each other.

In humans, the extent of CYP2E1 induction is individually determined, but may be significant following the ingestion of $40 \mathrm{~g}$ alcohol per day, corresponding to $400 \mathrm{ml}$ of 12.5 vol. \% wine, for 1 week (Oneta et al., 2002). ROS produced by CYP2E1 lead to lipid peroxidation, with the generation of malondialdehyde (MDA) and 4-HNE (Aleynik et al., 1998). 4-HNE not only leads to a mutation at codon 249 , which makes cells more resistant to apoptosis and shows some growth advantages (Hu et al., 2002), but also causes the production of exocyclic DNA etheno adducts $(\varepsilon d A)$, which can be measured in urine and determined immunohistologically in the liver (Frank et al., 2004). It has been shown that 
these adducts are present in alcoholic fatty, liver but are more pronounced in advanced ALDs such as cirrhosis. Adduct formation is somewhat comparable with those found in iron storage disorders such as hemochromatosis and Wilson's disease. Some evidence suggests that the degree of CYP2E1 induction in cell cultures can be correlated with the extent of $\varepsilon \mathrm{dA}$.

With respect to the effect of ethanol on the generation of mitochondrial ROS, readers are referred to recent review articles (Hoek et al., 2002; Albano, 2005).

The steady-state level of DNA adducts is influenced by various factors and is elevated under the following conditions: (1) reduction of the antioxidative defense system; (2) diminished glutathione $S$-transferase due to genetic polymorphism; (3) an impaired DNA repair system; and (4) reduced apoptosis. Chronic ethanol ingestion may favor factors 1, 2, and 4 either directly or via chronic inflammation.

Alteration of the antioxidative defense system and inhibition of DNA repair The increased oxidative stress observed during ethanol metabolism leads to an increase in the requirement for glutathione and $\alpha$-tocopherol. Chronic alcoholism also increases the requirement for methyl groups, and dietary methyl deficiency may enhance hepatic carcinogenesis (Stickel and Seitz, 2004). In ALD, the hepatic glutathione content is significantly reduced. It has been shown that supplementation with $\mathrm{N}$-acetylcysteine prevents liver injury in experimental alcohol-induced hepatic injury (Limuro et al., 2000; Ronis et al., 2005). Since mitochondrial glutathione content is reduced by $50-85 \%$ (Fernandez-Checa et al., 1991), it is not surprising that this favors mitochondrial dysfunction and lipid peroxidation, and impairs hepatocyte tolerance to TNF- $\alpha$ (Fernandez-Checa and Kaplowitz, 2005). In addition, $\alpha$-tocopherol is also reduced due to enhanced oxidation (Kawase et al., 1989). More recently, a decrease in enzyme activity and the immunoreactive protein concentration of hepatic (Cu-Zn)-superoxide dismutase, catalase and glutathione peroxidase in experimental ALD has been reported (Rouacht et al., 1997), which inversely correlated with the extent of lipid peroxidation and hepatic injury (Polavarapu et al., 1998). Subsequently, selenium deficiency has been reported in alcoholics (Seitz and Suter, 2002).

Chronic alcohol consumption also inhibits hepatic DNA repair induced by nitrosamines. This is due to acetaldehyde-related inhibition of $\mathrm{O}^{6}$-guanine-methyl transferase (Espina et al., 1988) (Figure 3).

\section{Disturbed methyl group transfer}

Changes in the degree of methylation of cytosine are frequently encountered in human cancers, but their relevance as an epigenetic factor in carcinogenesis is only partially understood (Counts and Goodman, 1995). However, DNA methylation is an important determinant in controlling gene expression, whereby hypermethylation has a silencing effect on genes and hypomethylation may lead to increased gene expression. In hepatocarcinogenesis, general hypomethylation may be coupled with areas of regional hypermethylation. Thus, hypermethylation of tumor suppressor genes can result in decreased gene transcription of $p 53$ and HIC-1 (Kanai et al., 1999), and hypomethylation of certain oncogenes such as c-myc and $\mathrm{c}-\mathrm{N}$-ras may lead to dedifferentiation and proliferation (Wainfan et al., 1989; Wainfan and Poirier, 1992; Shen et al., 1998).

Recently, it has been suggested that aberrant DNA hypermethylation may be associated with genetic instability, as determined by the loss of heterozygosity and microsatellite instability in human HCC due to chronic viral hepatitis (Kanai et al., 2000; Kondo et al., 2000). Iwata et al. (2000) detected hypermethylation of the 143-3 $\sigma$ gene, which has been implicated as a key inducer of cell cycle arrest associated with p53 in $89 \%$ of human HCC investigated. However, genetic alterations in animal models and human hepatocarcinogenesis differ substantially. Thus, it was shown that activation of $\mathrm{N}-m y c$ and c-myc oncogenes is frequent in woodchuck hepatitis virus-associated $\mathrm{HCC}$, while no p53 mutations were found. This mutational pattern is reversed in humans, where $p 53$ are frequent and oncogene activation seems to play only a minor role (Hui and Makuuchi, 1999).

Importantly, modifications of the degree of hepatic DNA methylation have also been observed in experimental models of chronic alcoholism (Garro et al., 1991; Choi et al., 1999). Hypomethylation is a plausible consequence of metabolic alterations in the setting of ethanol consumption. In fact, alcohol has a marked impact on hepatic methylation capacity, as reflected by decreased levels of $S$-adenosylmethionine (SAM), an important methyl group donor, and increased levels of $S$ adenosylhomocysteine (SAH), resulting in an up to 2.5fold decrease in the SAM/SAH ratio (Lieber et al., 1990; Trimble et al., 1993; Stickel et al., 2000). Several mechanisms have been suggested by which ethanol could interact with one-carbon metabolism and DNA methylation and thereby enhance carcinogenesis (Lu and Mato, 2005). (1) Chronic alcohol interacts with intake, absorption and subsequent metabolism of B vitamins involved in hepatic transmethylation reactions, namely folate and pyridoxal-5'-phosphate (vitamin $B_{6}$ ), resulting in impaired methyl group synthesis and transfer (Lumeng and $\mathrm{Li}$, 1974; Labadarios et al., 1977; Savage and Lindenbaum, 1986; Gloria et al., 1997; Stickel et al., 2000). (2) Ethanol reduces the activity of methionine synthetase, which remethylates homocysteine to methionine with methyltetrahydrofolate as the methyl donor (Barak et al., 1993; Lieber, 1994). (3) Chronic alcohol consumption decreases glutathione levels, a reductive tripeptide that is synthesized from homocysteine via trans-sulfuration in the liver, and thereby enhances the susceptibility of the liver to alcohol-related peroxidative damage (Speisky et al., 1985; Lieber, 1994). (4) Alcohol can inhibit the activity of DNA methyltransferase, which transfers methyl groups to DNA in rats (Lieber et al., 1990), a finding that could not, however, be confirmed in humans (Miyakawa et al., 1996).

To date, it is well established that dietary depletion of lipotropes, including methionine, choline, betaine, SAM and folate, leads to DNA hypomethylation, particularly hypomethylation of oncogenes (that is $\mathrm{C}-\mathrm{Ha}$-ras, $\mathrm{C}-\mathrm{Ki}$-ras and $c$-fos) and to DNA strand breaks, all of which are associated with an increased incidence of HCC in rats 
(Zapisek et al., 1992; Pogribny et al., 1995). Figure 5 illustrates methyl transfer and alcohol interactions.

\section{Interaction with retinoids}

Another important issue in hepatocarcinogenesis relates to the metabolism and functions of retinoids (Seitz, 2000; Wang, 2005). Chronic alcohol consumption interferes strikingly with the metabolism of retinol and retinoic acid (RA) factor (see below). Reduced serum and hepatic vitamin A concentrations have been shown in chronic alcoholics (Leo and Lieber, 1982). This is of particular importance, as RA is synthesized from retinol via various enzymatic steps involving microsomal and cytosolic ADH and ALDH. RA has profound effects on cellular growth and differentiation via two families of RA nuclear receptors (RAR- $\alpha,-\beta$ and $-\chi$, and RXR $-\alpha,-\beta$ and $-\chi$ ), which mediate RA-induced gene transcription (Chambon, 1996). In a series of experiments, the effects of alcohol on retinol and RA metabolism, on transcellular RA signaling, and on early events of carcinogenesis have been investigated. Chronic alcohol consumption affects several aspects of degradation in the liver and increased mobilization of retinol from the liver to other organs (Leo and Lieber, 1999; Seitz, 2000). These ethanol-induced changes may result in decreased hepatic concentrations of both retinol and retinyl esters, which are the metabolically active precursors of RA. Furthermore, it has been demonstrated that ethanol acts as a competitive inhibitor of retinol oxidation in the liver, thereby counteracting the biosynthesis of RA (Wang et al., 1998). Accordingly, RA levels in the liver of ethanol-fed rats were significantly decreased compared with control pairs fed an isocaloric control diet containing equal amounts of vitamin A (Liu et al., 2001). It has recently been shown that ethanol causes an additional local deficiency of RA in the liver, resulting from enhanced $R A$ catabolism due to induction of CYP2E1 (Chung et al., 2001). In the same study, treatment of ethanol-fed rats with chlormethiazole, a specific CYP2E1 inhibitor, restored both hepatic and plasma RA concentrations to normal levels. Enhancement of RA catabolism by ethanol in vitro was inhibited by CYP2E1 antibodies and chlormethiazole, while catabolism of RA into polar metabolites was abolished completely by nonspecific cytochrome P450 inhibitors. Lastly, chronic alcohol consumption resulted in a functional downregulation of $\mathrm{RA}$ receptors and up to eight-fold higher expression of the AP-1 (c-jun and c-fos) transcriptional complex (Wang et al., 1998). This explains parenchymal hyperproliferation, as AP-1 is a central complex downstream of various growth factors, oncogenes and tumor promoters (Chiu et al., 1988). Most interestingly, supplementation of animals with all-trans-RA to normal RA levels not only led to a decrease in AP-1 (c-jun and c-fos) gene expression, but also to normalization of hepatic proliferation, as expressed by proliferating cell nuclear antigen expression (Chung et al., 2001). In summary, these data suggest that low hepatic RA levels due to chronic alcohol misuse may favor proliferation and malignant transformation of hepatocytes via upregulation of AP-1 (c-jun and c-fos) gene expression. (Figures 6 and 7).

Accordingly, retinoids inhibit chemically induced liver cancer in animals (Moreno et al., 2002). In addition, an

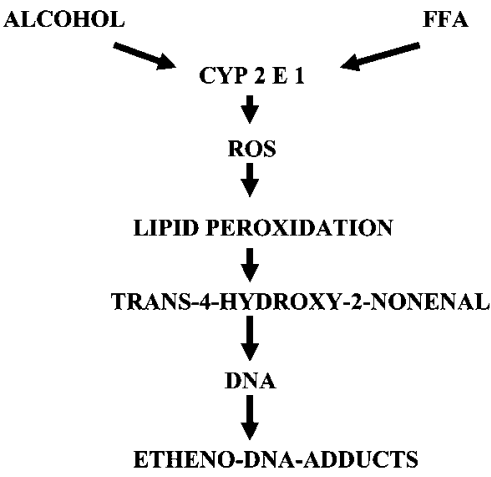

Figure 5 Production of etheno-DNA adducts via induction of cytochrome P-4502E1 and lipid peroxidation.

FFA: free fatty acids.

inverse relationship between the risk of $\mathrm{HHC}$ and $\mathrm{RA}$ levels has been observed (Yu et al., 1995, 1999) and the administration of a synthetic retinoid prevented the occurrence of a secondary cancer in patients with HCC (Muto et al., 1999).

\section{Iron and oxidative stress}

As pointed out above, the risk for $\mathrm{HCC}$ in hereditary hemochromatosis is approximately 200 -fold higher than in the general population. The increased risk of HCC may be the result of generation of ROS from free iron, directly through the Fenton reaction or indirectly through acceleration of lipid peroxidation (Petersen, 2005). Iron leads to DNA strand breaks and to $p 53$ mutation via 4-HNE, a major lipid peroxidation product (Marrogi et al., 2001; Bartsch and Nair, 2004). In addition, these products also result in DNA adducts, as well as in an activation of stellate cells, followed by enhanced fibrogenesis. Chronic alcohol ingestion increases the intestinal uptake and hepatic deposition of iron. It has been shown that the presence of iron, particularly low-molecular-weight non-

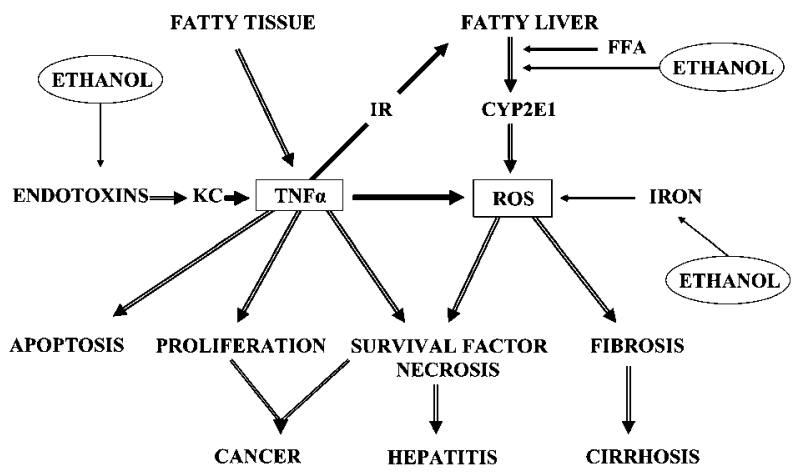

Figure 6 Progression of alcoholic and non-alcoholic fatty liver to advanced liver disease in fatty liver.

Cytochrome P-4502E1 (CYP2E1) is induced by ethanol and/or free fatty acids, which results in the generation of reactive oxygen species (ROS). In addition, tumor necrosis factor $\alpha$ (TNF- $\alpha$ ) is generated from fatty tissue or released from Kupffer cells (KC) via gut-derived endotoxins. TNF- $\alpha$ leads to insulin resistance and to the production of ROS. Both TNF- $\alpha$ and ROS result in alteration of cell biology favoring the progression of liver disease and carcinogenesis. 


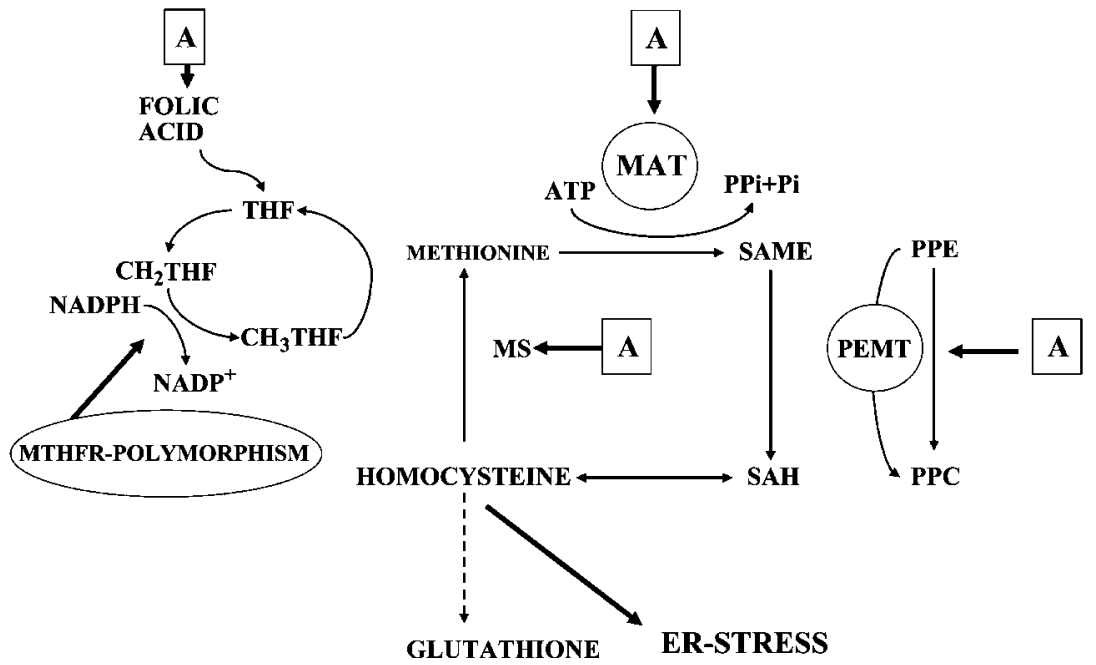

Figure 7 Effect of ethanol on methyl group transfer.

Chronic ethanol consumption (A) results in a decrease in folic acid, and inhibition of methionine synthase (MS), methionine adenosinetransferase (MAT) and phosphoethanolamine methyltransferase (PEMT). As a result, hepatic levels of $S$-adenosylmethionine (SAME) are decreased and homocysteine concentrations are increased, leading to endoplasmic reticulum (ER) stress.

$\mathrm{THF}$, tetrahydrofolate; $\mathrm{NADP}^{+}$, nicotine adenine dinucleotide phosphate; NADPH, nicotine adenine dinucleotide phosphate (reduced); PPE, polyenylphosphoethanolamine; PPC, polyenylphosphocholine.

protein iron complexes, exacerbates oxidative damage by alcohol and that it stimulates hepatic macrophages to produce ROS and pro-inflammatory cytokines (Tsukamoto et al., 1999; Caro and Cederbaum, 2004). Although the mechanism of ethanol-associated hepatic iron deposition is still unclear, it has been speculated that oxidative modification of cytosolic iron regulatory protein 1 (IRP1) causes repression of ferritin synthesis and stimulation of transferring receptor synthesis, with increased iron uptake (Rouault, 2003).

\section{Summary and conclusions}

$\mathrm{HCC}$ is a frequently occurring cancer worldwide. A variety of risk factors exist, including $\mathrm{HBV}$ and $\mathrm{HCV}$ infection, NAFLD, heavy alcohol consumption and aflatoxin exposure. Most HCCs occur in cirrhotic livers and the common mechanism for hepatocarcinogenesis is chronic inflammation associated with severe oxidative stress. Oxidative stress in ALD is due to a variety of factors, such as the production of acetaldehyde from ethanol, the induction of CYP2E1, a decrease in the antioxidative defense system, disturbed metabolism of retinoids and methyl groups, and iron overload. Conclusions drawn from the fact that oxidative stress is a major pathophysiological factor in the development of HCC may include preventive and interventional therapeutic approaches with antioxidants. Such approaches have been initiated with retinoids, but clinical data are still inconclusive and further clinical studies are urgently needed. However, the best method for prevention of HCC is vaccination against hepatitis B, avoidance of infection with hepatitis $C$ by optimal hygienic measures, avoidance of food contaminated with aflatoxins, reduction of alcohol intake to safe limits (20-30 g for men, 10-20 g for women) and maintenance of a normal body weight to avoid diabetes and metabolic syndrome. Finally, early diagnosis of hereditary hemochromatosis with consequent treatment by phlebotomy will prevent the occurrence of HCC.

\section{References}

Albano, E. (2002). Free radicals and alcohol-induced liver injury. In: Ethanol and the Liver, C.D.I.N. Sherman, V.R. Preedy and R.R. Watson, eds. (London, UK: Taylor and Francis), pp. 153-190.

Albano, E., Clot, P., Morimoto, M., Tomasi, A., and Dianzani, M.U. (1993). Evidence for the covalent binding of hydroxyethyl radicals to rat liver microsomal proteins. Alcohol Alcohol. 28, 453-459.

Aleynik, S.I., Leo, M.A., Aleynik, M.K., and Lieber, C.S. (1998). Increased circulating products of lipid peroxidation in patients with alcoholic liver disease. Alcohol. Clin. Exp. Res. 22, 192-196.

Arteel, G.E. (2003). Oxidant and antioxidant in alcohol-induced liver disease. Gastroenterology 124, 778-790.

Bailey, S.M. and Cunningham, C.C. (2002). Contribution of mitochondria to oxidative stress associated with alcohol liver disease. Free Radic. Biol. Med. 32, 11-16.

Barak, A.J., Beckenhauer, H.C., Hidiroglou, N., Camilo, M.E., Selhub, J., and Tuma, D.J. (1993). The relationship of ethanol feeding to the methyl folate trap. Alcohol 10, 495-497.

Bardag-Gorce, F., Yuan, Q.X., Li, J., French B.A., Fang, C., Ingelmann-Sundberg, M., and French, S.W. (2000). The effect of ethanol induced cytochrome P-45o2E1 on the inhibition of proteasome activity by alcohol. Biochem. Biophys. Res. Commun. 279, 23-29.

Bartsch, H. and Nair, J. (2004). Oxidative stress and lipid peroxidation-derived DNA-lesions in inflammation driven carcinogenesis. Cancer Detect. Prev. 28, 385-391.

Bautista, A.P. (2002). Neutrophilic infiltration in alcoholic hepatitis. Alcohol 27, 17-21.

Beckmann, J.S. and Koppenol, W.H. (1996). Nitric oxide, superoxide and peroxynitrite: the good, the bad and the ugly. Am. J. Physiol. 271, C1424-C1437. 
Becker, U., Dies, A., and Sorensen, T.I. (1996). Prediction of risk of liver disease by alcohol intake, sex, and age: prospective population study. Hepatology 23, 1025-1029.

Benvegnu, L., Fattovich, G., Noventa, F., Tremolada, F., Chemello, L., Cecchetto, A., and Alberti, A. (1994). Concurrent hepatitis $B$ and $C$ virus infection and risk of hepatocellular carcinoma in cirrhosis. Cancer 74, 2442-2448.

Bluteau, O., Beaudoin, J.C., Pasturaus, P., Belghiti, J., Franco, D., Bioulac-Sage, P., Laurent-Puig, P., and Zacman-Rossi, J. (2002). Specific association between alcohol intake, high grade of differentiation and 4q34-q35 deletions in hepatocellular carcinomas identified by high resolution allelotyping. Oncogene 21, 1225-32.

Bolondi, L., Sofia, S., Siringo, S., Gaiani, S., Casali, A., Zironi, G., Piscaglia, F., Gramantieri, L., Zanetti, M., and Sherman, M. (2001). Surveillance programme of cirrhotic patients for early diagnosis and treatment of hepatocellular carcinoma: a cost effectiveness analysis. Gut 48, 251-259.

Borzio, M., Bruno, S., Roncalli, M., Colloredo Meis, G., Ramella, G., Borio, F., Leandro, G., Servida, E., and Podda, M. (1995). Liver cell dysplasia is a major risk factor for hepatocellular carcinoma in cirrhosis: a prospective study. Gastroenterology 108, 812-817.

Borzio, M., Fargion, S., Borzio, F., Fracanzani, A.L., Croce, A.M. Stroffolini, T., Oldani, S., Cotechini, R., and Roncalli, M. (2003). Impact of large regenerative low-grade and highgrade dysplastic nodules in hepatocellular carcinoma development. J. Hepatol. 39, 208-214.

Bosch, F.X., Ribes, J., and Borras, J. (1999). Epidemiology of primary liver cancer. Sem. Liver Dis. 19, 271-285.

Bosch, F.X., Ribes, J., Diaz, M., and Cléries, R. (2004). Primary liver cancer: worldwide incidence and trends. Gastroenterology 127, S5-16.

Bradford, B.U., Kona, H., Isayama, F., Kosyk, O., Wheeler, M.D., Akiyama, T.E., Bleye, L., Krausz, K.W., Gonzalez, F.J., Koop, D.R., and Rusyn, I. (2005). Cytochrome P-450 CYP2E1, but not nicotinamide adenine dinucleotide phosphate oxidase is required for ethanol-induced oxidative DNA damage in rodent liver. Hepatology 41, 336-344.

Bréchot, C. (2004). Pathogenesis of hepatitis B virus-related hepatocellular carcinoma: old and new paradigms. Gastroenterology 127, S56-S61.

Brooks, P.J. and Theruvathu, J.A. (2005). DNA adducts from acetaldehyde: implications for alcohol-related carcinogenesis. Alcohol 35, 187-193.

Caro, A.A. and Cederbaum, A.I. (2004). Oxidative stress, toxicology and pharmacology of CYP2E1. Annu. Rev. Pharmacol. Toxicol. 44, 27-42.

Chambon, P. (1996). A decade of molecular biology of retinoic acid receptors. FASEB J. 10, 940-954.

Chamulitrat, W. and Spitzer, J.J. (1996). Nitric oxide and liver injury in alcohol fed rats after lipopolysaccharide administration. Alcohol. Clin. Exp. Res. 20, 1065-1070.

Chiu, R., Boyle, W.J., Meek, J., Smeal, T., Hunter, T., and Karin, M. (1988) c-fos protein interacts with c-jun/AP-1 to stimulate transcription of AP-1 responsive genes. Cell 54, 541-552.

Choi, S.W., Stickel, F., Baik, H.W., Kim, Y.I., Seitz, H.K., and Maison, J.B. (1999). Chronic alcohol consumption induces genomic but not p53 specific DNA hypomethylation in rat colon. J. Nutr. 129, 1945-1950.

Chung, J., Liu, C., Smith, D.E., Seitz, H.K., Russel, R.M., and Wang, X.D. (2001). Restoration of retinoic acid concentration suppresses ethanol induced c-jun overexpression and hepatocyte hyperproliferation in rat liver. Carcinogenesis 22, 1213-1219.

Clot, P., Bellomo, G., Tabone, M., Arico, S., and Albano, E. (1995). Detection of antibodies against proteins modified by hydroxyethyl free radicals in patients with alcoholic cirrhosis. Gastroenterology 108, 210-207.

Clot, P., Albano, E., Elliasson, E., Tabone, M., Arico, S., Israel, Y., Moncada, Y., and Ingelman-Sundberg, M. (1996). Cytochrome P4502E1 hydroxyethyl radical adducts as the major antigenic determinant for autoantibody formation among alcoholics. Gastroenterology 111, 206-216.

Counts, J.L. and Goodman, J.I. (1995). Alterations in DNA methylation play a variety of roles in carcinogenesis. Cell 83 , 13-15.

Dellarco, V.L. (1988). A mutagenicity assessment of acetaldehyde. Mutat. Res. 195, 1-20.

Denissenko, M.F., Koudriakova, T.B., Smith, L., O'Connor, T.R., Riggs, A.D., and Pfeifer, G.P. (1998). The p53 codon 249 mutational hotspot in hepatocellular carcinoma is not related to selective formation or persistence of aflatoxin B1 adducts. Oncogene 17, 3007-3014.

Deutsche Hauptstelle für Suchtfragen (2003). Jahrbuch Sucht (Geesthacht, Germany: Neuland Verlagsgesellschaft $\mathrm{mbH}$ ).

Donato, F., Tagger, A., Gelatti, U., Parrinello, G., Moffetta, P., Alberini, A., Decarli, A., Travisi, P., Ribero, M.L., Martelli, C., et al. (2002). Alcohol and hepatocellular carcinoma: the effect of lifetime intake and hepatitis virus infections in men and women. Am. J. Epidemiol. 155, 323-331.

Donato, M.F., Arosio, E., Del Ninno, E., Ronchi, G., Lampertico, P., Morabito, A., Balestrieri, M.R., and Colombo, M. (2001). High rates of hepatocellular carcinoma in cirrhotic patients with high liver cell proliferative activity. Hepatology 34 , 523-528.

Dupont, I., Lucas, D., Clot, P., Ménez, C., and Albano, E. (1998). Cytochrome P4502E1 inducibility and hydroxyethyl radical formation among alcoholics. J. Hepatol. 28, 564-571.

El-Serag, H.B. (2004). Hepatocellular carcinoma: recent trends in the United States. Gastroenterology 127, S27-S34.

El-Serag, H.B. and Mason, A.C. (2000). Risk factors for the rising rates of primary liver cancer in the Untied States. Arch. Intern. Med. 160, 3227-3230.

Espina, N., Lima, V., Lieber, C.S., and Garro, A.J. (1988). In vitro and in vivo inhibitory effect of ethanol and acetaldehyde on $\mathrm{O}^{6}$-methylguanine transferase. Carcinogenesis 9, 761-766.

Fang, J.L. and Vaca, C.E. (1997). Detection of DNA adducts of acetaldehyde in peripheral white blood cells of alcohol abusers. Carcinogenesis 18, 627-632.

Fattovich, G., Stroffolini, T., Zagni, I., and Donato, F. (2004). Hepatocellular carcinoma in cirrhosis: incidence and risk factors. Gastroenterology 127, S35-S50.

Ferlay, J., Bray, F., Pisani, P., and Parkin, D.M. (2001). Cancer Incidence, Mortality and Prevalence Worldwide. Version 1.0 (Lyon, France: IARC Press).

Fernandez-Checa, J.C. and Kaplowitz, N. (2005). Hepatic mitochondrial glutathione: transport and role in disease and toxicity. Toxicol. Appl. Pharmacol. 204, 263-273.

Fernandez-Checa, J.C., Garcia-Ruiz, C., Ookhtens, M., and Kaplowitz, N. (1991). Impaired uptake of glutathione by hepatic mitochondria from ethanol fed rats. J. Clin. Invest. 87, 397-405.

Frank, A., Seitz, H.K., Bartsch, H., Frank, N., and Nair, J. (2004). Immunohistochemical detection of $1, N^{6}$-ethenodeoxyadenosine in nuclei of human liver affected by diseases predisposing to hepatocarcinogenesis. Carcinogenesis 25, 1027-1031.

French, S., French, B., Dedes, J., Li, J., Barda-Gorce, F., and Nan, L. (2005). What is the Mallory body-forming cell phenotype? What is the relevance to hepatoma formation? Alcohol Alcohol. 40 (Suppl. 1), i35-36.

Ganne-Carrié, N., Chastang, C., Chapel, F., Munc, C., Pateron, D., Sibony, M., Dèny, P., Trinchet, J.C., Callard, P., Guettier, C., and Beaugrand, M. (1996). Predictive score for the development of hepatocellular carcinoma and additional value of liver large cell dysplasia in Western patients with cirrhosis. Hepatology 23, 1112-1118.

Garcia-Ruiz, C., Colell, A., Paris, R., and Fernandez-Checa, J.C. (2000). Direct interaction of GD3 ganglioside with mitochondria generates reactive oxygen species followed by mitochondrial permeability transition, cytochrome $c$ release and caspase activation. FASEB J. 14, 847-850. 
Garro, A.J., McBeth, D.L., Lima, V., and Lieber, C.S. (1991). Ethanol consumption inhibits fetal DNA methylation in mice: implication for the fetal alcohol syndrome. Alcohol. Clin. Exp. Res. 15, 395-398.

Gloria, L., Cravo, M., Camilo, M.E., Rsende, M., Cardoso, J.N., Oliveira, A.G., Leitao, C.N., and Mira, F.C. (1997). Nutritional deficiencies in chronic alcoholics: relation to dietary intake and alcohol consumption. Am. J. Gastroenterol. 92, 485489.

Gouillon, Z., Lucas, D., Li, J., Hagbjork, A.L., French, B.A., Fu, P., Fang, C., Ingelman-Sundberg, M., Donohue, T.M., and French, S.W. (2000). Inhibition of ethanol-induced liver disease in the intragastric feeding rat model by chlormethiazole. Proc. Soc. Biol. Med. 224, 302-308.

Grant, B., Harfort, T., Dawson, D., Chou, P., DuFour, M., and Pickering, R. (1994). Prevalence of DSM-IV alcohol abuse and dependence: United States, 1992. Alcohol Health Res. World 18, 243-248.

Hassan, M.M., Hwang, L.Y., Hatten, C.J., Swaim, M., Li, D., Abbruzzese, J.L., Beasley, P., and Patt, Y.Z. (2002). Risk factors for hepatocellular carcinoma: synergism of alcohol with viral hepatitis and diabetes mellitus. Hepatology 36, 1206-1213.

Helander, A. and Lindahl-Kiessling, K. (1991). Increased frequency of acetaldehyde-induced sister-chromatide exchanges in human lymphocytes treated with an aldehyde dehydrogenase inhibitor. Mutat. Res. 264, 103-107.

Hines, I.N. and Wheeler, M.D. (2004). Recent advances in alcoholic liver disease III. Role of the innate immune response in alcoholic hepatitis. Am. J. Physiol. 287, G310-314.

Hoek, J.B., Cahill, A., and Pastorino, J.G. (2002). Alcohol and mitochondria: a dysfunctional relationship. Gastroenterology 122, 2049-2063.

Homann, N., Stickel, F., König, I.R., Jacobs, A., Junghanns, K., Benesova, M., Schuppan, D., Himsel, S., Zuber-Jerger, I., Hellerbrand, C., et al. (2006). Alcohol dehydrogenase $1 C^{* 1}$ allele is a genetic marker for alcohol associated cancer in heavy drinkers. Int. J. Cancer 118, 1998-2002.

Hu, W., Feng, Z., Eveleigh, J., Iyer, G., Pan, J., Amin, S., Chung, F.L., and Tang, M.S. (2002). The major lipid peroxidation product, trans-4-hydroxy-2-nonenal, preferentially forms DNA adducts at codon 249 of human p53 gene, a unique mutational hot spot in hepatocellular carcinoma. Carcinogenesis 23, 1781-1789.

Hui, A.M. and Makuuchi, M. (1999). Molecular basis of multistep hepatocarcinogenesis: genetic and epigenetic events. Scand. J. Gastroenterol. 8, 737-742.

IARC (1999). Acetaldehyde IARC monographs on the evaluation of the carcinogenic risk to humans. Reevaluation of some organic chemicals, hydrazines and hydrogen peroxides. Lyon Int. Agency Res. Cancer 71, 319-335.

limuro, Y., Bradford, B.U., Yamashina, S., Rusyn, I., Nakagami, M., Enomoto, N., Kono, H., Frey, W., Forman, D., Brenner, D., and Thurman, R.G. (2000). The glutathione precursor L2-oxothiazolidine-4-carboxylic acid protects against liver injury due to chronic enteral ethanol exposure in the rat. Hepatology 31, 391-398.

Inoué, H. and Seitz, H.K. (2001). Viruses and alcohol in the pathogenesis of primary hepatic carcinoma. Eur. J. Cancer Prev. $10,1-4$.

Iwata, N., Yamamoto, H., Sasaki, S., Itoh, F., Suzuki, H., Kikuchi, T., Kaneto, H., Iku, S., Ozeki, I., Karino, Y., et al. (2000). Frequent hypermethylation of $\mathrm{CpG}$ islands and loss of expression of the 14-3-3 $\sigma$ gene in human hepatocellular carcinoma. Oncogene 19, 5298-5302.

Jarvelainen, H.A., Fang, C., Ingelman-Sundberg, M., and Lindros, K.O. (1999). Effect of chronic coadministration of endotoxin and ethanol on rat liver pathology and proinflammatory and antiinflammatory cytokines. Hepatology 29, 1503-1510.
Kanai, Y., Hui, A.M., Sun, L., Ushijima, S., Sakramoto, M., Tsuda, H., and Hirohashi, S. (1999). DNA hypermethylation at the D17S5 locus and reduced HIC-1 mRNA expression are associated with hepatocarcinogenesis. Hepatology 29, 703-709.

Kanai, Y., Ushijima, S., Tsuda, H., Sakamoto, M., and Hirohashi, S. (2000). Aberrant DNA methylation precedes loss of heterozygosity on chromosome 16 in chronic hepatitis and liver cirrhosis. Cancer Lett. 148, 73-80.

Kawase, T., Kato, S., and Lieber, C.S. (1989). Lipid peroxidation and antioxidant defense systems in rat liver after chronic ethanol feeding. Hepatology 10, 815-821.

Ketcham, A.S., Wexler, H., and Mantel, N. (1963). Affects of alcohol in mouse neoplasia. Cancer Res. 23, 667-670.

Kondo, Y., Kanai, Y., Sakamoto, M., Mizokami, M., Ueda, R., and Hirohashi, S. (2000). Genetic instability and aberrant DNA methylation in chronic hepatitis and cirrhosis - a comprehensive study of loss of heterozygosity and microsatellite instability at 39 loci and DNA hypermethylation on $8 \mathrm{CpG}$ islands in microdissected specimens from patients with hepatocellular carcinoma. Hepatology 32, 970-979.

Kowdley, K.V. (2004). Iron, hemochromatosis, and hepatocellular carcinoma. Gastroenterology 127, S79-S86.

Labadarios, D., Rossouw, J.E., McConnell J.B., Davis, M., and Williams, R. (1977). Vitamin B6 deficiency in chronic liver disease - evidence for increased degradation of pyridoxal-5phosphate. Gut 18, 23-27.

Laurent-Puig, P., Legoix, P., Bluteau, O., Belghiti, J., Franco, D., Binot, F., Monges, G., Thomas, G., Bioulac-Sage, P., and Zucman-Rossi, J. (2001). Genetic alterations associated with hepatocellular carcinomas define distinct pathways of hepatocarcinogenesis. Gastroenterology 120, 1763-1773.

Leo, M.A. and Lieber, C.S. (1982). Hepatic vitamin A depletion in alcoholic liver injury. N. Engl. J. Med. 304, 597-600.

Leo, M.A. and Lieber, C.S. (1999). Alcohol, vitamin A, and betacarotene: adverse interactions, including hepatotoxicity and carcinogenicity. Am. J. Clin. Nutr. 69, 1071-1085.

Liang, T.J. and Heller, T. (2004). Pathogenesis of hepatitis Cassociated hepatocellular carcinoma. Gastroenterology 127 , S62-S71.

Lieber, C.S. (1994). Alcohol and the liver: 1994 update. Gastroenterology 106, 1085-1105.

Lieber, C.S., Casini, A., DeCarli, L.M., Kim, C.I., Lowe, N., Sasaki, R., and Leo, M.A. (1990). S-Adenosyl-L-methionine attenuates alcohol-induced liver injury in the baboon. Hepatology $11,165-172$

Lin, M.T., Juan, C.Y., Chang, K.J., Chen, W.J., Kuo, M.L. (2001). IL-6 inhibits apoptosis and retains oxidative DNA lesions in human gastric cancer AGS cells through up-regulation of anti-apoptotic gene mcl-1. Carcinogenesis 22, 1947-1953.

Liu, C., Russel, R., Seitz, H.K., and Wang, X.D. (2001). Ethanolenhances retinoic acid metabolism into metabolites in rat liver via induction of cytochrome P-4502E1. Gastroenterology $120,179-189$

Lu, S.C. and Mato, J.M. (2005). Role of methionine adenosyltransferase and $S$-adenoxylmethionine in alcohol-associated liver cancer. Alcohol 35, 227-234.

Lumeng, L. and Li, T.K. (1974). Vitamin B6 metabolism in chronic alcohol abuse. J. Clin. Invest. 53, 693-704.

Marrogi, A.J., Khan, M.A., van Gijssel, H.E., Welsh, J.A., Rahim H., Demetris, A.J., Kowdley, K.V., Hussain, S.P., Nair, J., Bartsch, H., et al. (2001). Oxidative stress and p53 mutations in the carcinogenesis of iron overload-associated hepatocellular carcinoma. J. Natl. Cancer Inst. 93, 1652-1655.

Matsuda, T., Terashima, I., Matsumoto, Y., Yabushita, H., Matsui, S., and Shibutani, S. (1999). Effective utilization of $N^{2}$-ethyl$2^{\prime}$-deoxyguanosine triphosphate during DNA synthesis catalyzed by mammalian replicative DNA polymerases. Biochemistry 38, 929-935.

McKillop, I.H. and Schrum, L.W. (2005). Alcohol and liver cancer. Alcohol 35, 195-203. 
Miyakawa, H., Liu, J., Noguchi, O., Marumo, F., and Sato, C. (1996). Effect of alcohol drinking on gene expression of hepatic $\mathrm{O}^{6}$-methylguanine DNA methyltransferase in chronic liver diseases. Alcohol. Clin. Exp. Res. 20, 297A-300A.

Moreno, F.S., Yu, T.S., Naves, M.M.V., Silveira, E.R., Oloris, S.C., daCosta, M.A.L., Dagli, M.L.Z., and Ong, T.P. (2002). Inhibitory effects of $\beta$-carotene and vitamin A during the progression phase of hepatocarcinogenesis involve inhibition of cell proliferation but not alterations in DNA methylation. Nutr. Cancer 44, 80-88.

Morgan, K., French, S.W., and Morgan, T.R. (2002). Production of a cytochrome P-4502E1 transgenic mouse and initial evaluation of alcoholic liver damage. Hepatology 36, 122-134.

Morgan, T.R., Mandayam, S., and Jamal, M.M. (2004). Alcohol and hepatocellular carcinoma. Gastroenetrology 127, S87-S96.

Muto, Y., Moriwaki, H., and Saito, A. (1999) Prevention of second primary tumours by an acyclic retinoid in patients with hepatocellular carcinoma. N. Engl. J. Med. 340, 1046-1047.

Neuschwander-Tetri, B.A. and Caldwell, S.H. (2003). Nonalcoholic steatohepatitis: summary of an AASLD single topic conference. Hepatology 37, 1202-1219.

Obe, G., Jonas, R., and Schmidt, S. (1986). Metabolism of ethanol in vitro produces a compound which induces sisterchromatid exchanges in human peripheral lymphocytes in vitro: acetaldehyde not ethanol is mutagenetic. Mutat. Res. 174, 47-51.

Ohnishi, K. (1992). Alcohol and hepatocellular cancer. In: Alcohol and Cancer, R.R. Watson, ed. (Boca Raton, FL, USA: CRC Press), pp. 179-202.

Oneta, C.M., Lieber, C.S., Li, J.J., Ruttimann, S., Schmid, B., Lattmann, J., Rosman, A.S., and Seitz, H.K. (2002). Dynamics of cytochrome P4502E1 activity in man: induction by ethanol and disappearance during withdrawal phase. J. Hepatol. $36,47-52$.

Petersen, D.R. (2005). Alcohol, iron-associated oxidative stress, and cancer. Alcohol 35, 243-249.

Pogribny, I.P., Basnakian, A.G., Miller, B.J., Lopatina, N.G., Poirier, L.A., and James, S.J. (1995). Breaks in genomic DNA and within the $p 53$ gene are associated with hypomethylation in livers of folate/methyl-deficient rats. Cancer Res. 55, 1894-1901.

Polavarapu, R., Spitz, D.R., Sim, J.E., Follansbee, M.H., Oberley, L.W., Rahemtulla, A., and Nanji, A.A. (1998). Increased lipid peroxidation and impaired antioxidant enzyme function is associated with pathological liver injury in experimental alcoholic liver disease in rats fed diets high in corn oil and fish oil. Hepatology 27, 1317-1323.

Pöschl, G. and Seitz, H.K. (2004). Alcohol and cancer. Alcohol 39, 155-165.

Ronis, M.J.J., Butura, A., Sampey B.P., Prior, R.L., Kotourian, S., Albano, E., Ingelman-Sundberg, M., Petersen, D.R., and Badger, T.M. (2005). Effects of $N$-acetyl cysteine on ethanolinduced hepatotoxicity in rats fed via total enteral nutrition. Free Radic. Biol. Med. 39, 619-630.

Ross, R.K., Yuan, J.M., Yu, M.C., Wogan, G.N., Quian, G.S., Tu, J.T., Groopman, J.D., Gao, Y.T., and Henderson, B.E. (1992). Urinary aflatoxin biomarkers and risk of hepatocellular carcinoma. Lancet 339, 943-946.

Rouacht, H., Fattaccioli, V., Gentil, M., French, S.W., Morimoto, M., and Nordmann, R. (1997). Effect of chronic ethanol feeling on lipid peroxidation and protein oxidation in relation to liver pathology. Hepatology 25, 351-355.

Rouault, T.A. (2003). Hepatic iron overload in alcoholic liver disease: why does it occur and what is its role in pathogenesis? Alcohol 30, 103-106.

Savage, D. and Lindenbaum, J. (1986). Anaemia in alcoholics. Medicine 56, 322-328.

Seitz, H.K. (2000). Alcohol and retinoid metabolism. Gut 47, 748-750.
Seitz, H.K. and Osswald, B. (1992). Effect of ethanol on procarcinogen activation. In: Alcohol and Cancer, R.R. Watson, ed. (Boca Raton, FL, USA: CRC Press), pp. 55-72.

Seitz, H.K. and Suter, P.M. (2002). Ethanol toxicity and nutritional status. In: Nutritional Toxicology, 2nd Edition, F.N. Cotsones and M.A. McKay, eds. (London, New York: Taylor and Francis), pp. 122-154.

Seitz, H.K., Matsusaki, S., Yokoyama, A., Homann, N., Vakevainen, S., and Wang, X.D. (2001). Alcohol and cancer. Alcohol. Clin. Exp. Res. 25, 137-143.

Shen, L., Fang, J., Qiu, D., Zhang, T., Yang, J., Chen, S., and Xiao, S. (1998). Correlation between DNA methylation and pathological changes in human hepatocellular carcinoma. Hepatogastroenterology 45, 1753-1759.

Simanowski, U.A., Suter, P., Russell, R.M., Heller, M., Waldherr, R., Ward, R., Peters, T.J., Smith, D., and Seitz, H.K. (1994). Enhancement of ethanol induced rectal mucosal hyperregeneration with age in F-344 rats. Gut 35, 1102-1106.

Smela, M.E., Hamm, M.L., Henderson, P.T., Harris, C.M., Harris, T.M., and Essigmann, J.M. (2002). The aflatoxin B1 formamidopyrimidine adduct plays a major role in causing the types of mutations observed in human hepatocellular carcinoma. Proc. Natl. Acad. Sci. USA 99, 6655-6600.

Speisky, H., MacDonald, A., Giles, G., Orrego, H., and Israel, Y. (1985). Increased loss and decreased synthesis of hepatic glutathione after acute ethanol administration. Turnover studies. Biochem. J. 225, 565-572.

Stickel, F. and Österreicher, C.H. (2006). Genetic polymorphisms in alcoholic liver disease. Alcohol Alcohol., in press.

Stickel, F. and Seitz, H.K. (2004). Ethanol and methyl transfer: its role in liver disease and hepatocarcinogenesis. In: Nutrition and Alcohol: Linking Nutrient Interactions and Dietary Intake, R.R. Watson and V.R. Preedy, eds. (Boca Raton, FL, USA: CRC Press), pp. 57-72.

Stickel, F., Choi, S.W., Kim, Y.I., Bagley, P.J., Seitz, H.K., Russell, R.M., Sellhub, J., and Mason, J.B. (2000). Effect of chronic alcohol consumption on total plasma homocysteine level in rats. Alcohol. Clin. Exp. Res. 24,259-264.

Stickel, F., Schuppan, D., Hahn, E.G., and Seitz, H.K. (2002). Cocarcinogenic effects of alcohol in hepatocarcinogenesis. Gut 51, 132-139.

Tagger, A., Donato, F., Ribero, M.L., Chiesa, R., Portera, G., Gelatti, U., Alberini, A., Fasola, M., Moffetta, P., and Nardi, G. (1999). Case control study on hepatitis $\mathrm{C}$ virus (HCV) as a risk factor for hepatocellular carcinoma: the role of $\mathrm{HCV}$ genotypes and the synergism with hepatitis $B$ virus and alcohol. Brescia HCC study. Int. J. Cancer 81, 695-699.

Tarao, K., Rino, Y., Ohkawa, S., Shimizu, A., Tamai, S., Miyakawa, K., Aoki, H., Imada, T., Shindo, K., Okamoto, N., and Totsuka, S. (1999). Association between high serum alanine aminotransferase levels and more rapid development and higher rate of incidence of hepatocellular carcinoma in patients with hepatitis $C$ virus-associated cirrhosis. Cancer 86, 589-595.

Thurman, R.G. (1998). Alcoholic liver injury involves activation of Kupffer cells by endotoxins. Am. J. Physiol. 275, G605-G611.

Trerè, D., Borio, M., Morabito, A., Borio, F., Roncalli, M., and Derenzini, M. (2003). Nucleolar hypertrophy correlates with hepatocellular carcinoma development in cirrhosis due to HBV infection. Hepatology 37, 72-78.

Trimble, K.C., Molloy, A.M., Scott, J.M., and Weir, D.G. (1993). The effect of ethanol on one-carbon metabolism: increased methionine catabolism and lipotrope methyl-group wastage. Hepatology 18, 984-989.

Tsukamoto, H., Lin, M., Ohata, M., Giulivi, C., French, S.W., and Brittenham, G. (1999). Iron primes hepatic macrophages for NF-кB activation in alcoholic liver injury. Am. J. Physiol. 277, G1240-G1250.

Uesugi, T., Froh, M., Arteel, G.E., Bradford, B.U., and Thurman, 
R.G. (2001). Toll-like receptor 4 is involved in the mechanism of early alcohol induced liver injury in mice. Hepatology 34 , 101-108.

Urbaschek, R., McCuskey, R.S., Rudi, V., Becker, K.P., Stickel, F., Urbaschek, B., and Seitz, H.K. (2001). Endotoxin, endotoxin-neutralizing capacity, SCD14, sICAM-1, and cytokines in patients with various degrees of alcoholic liver disease. Alcohol. Clin. Exp. Res. 25, 261-268.

Wainfan, E. and Poirier, L.A. (1992). Methyl groups in carcinogenesis: effects on DNA methylation and gene expression. Cancer Res. 52 (Suppl. 7), 2071-2077.

Wainfan, E., Dizik, M., Stender, M., and Christman, J.K. (1989). Rapid appearance of hypomethylated DNA in livers of rats fed cancer-promoting, methyl-deficient diets. Cancer Res. 49, 4094-4097.

Wajant, H., Pfizenmaier, K., and Scheurich, P. (2003). Tumor necrosis factor signaling. Cell Death Differ. 10, 45-65.

Wang, D, Liu, C., and Chung, J. (1998). Chronic alcohol intake reduces retinoic acid concentration and enhances AP-1 (cjun and c-fos) expression in rat liver. Hepatology 28, $744-750$.

Wang, X.-D. (2005). Alcohol, vitamin A, and cancer. Alcohol 35, $251-258$

Yin, M., Bradford, B.U., Wheeler, M.D., Uesugi, T., Froh, M.,
Goyert, S.M., and Thurman, R.G. (2001). Reduced early alcohol induced liver injury in CD 14 deficient mice. J. Immunol. 166, 4737-4742.

Yokoyama, A., Muramatsu, T., Ohmori, T., Yokoyama, T., Okuyama, K., Takahashi, H., Hasegawa, Y., Higuchi, S., Maruyama, K., Shirakura, K., and Ishii, H. (1998). Alcohol-related cancers and aldehydrogenase-2 in Japanese alcoholics. Carcinogenesis 19, 1383-1387.

Yu, M.C. and Yuan, J.M. (2004). Environmental factors and risk of hepatocellular carcinoma. Gastroenterology 127, S72-S78.

Yu, M.W., Hsieh, H.H., Pan, W.H., Yang, C.S., and Chen, C.J. (1995). Vegetable consumption, serum retinol level and risk of hepatocellular carcinoma. Cancer Res. 55, 1301-1305.

Yu, M.W., Chiu, Y.H., Chiang, Y.C., Chen, C.H., Lee, T.H., Santella, R.M., Chern, H.D., Liaw, Y.F., and Chen, C.J. (1999). Plasma carotenoids, glutathione-S-transferase M1 and T1 genetic polymorphisms and risk of hepatocellular carcinoma: independent and interactive effects. Am. J. Epidemiol. 149, 621-629.

Zapisek, W.F., Cronin, G.M., Lyn-Cook, B.D., and Poirier, L.A. (1992). The onset of oncogene hypomethylation in the livers of rats fed methyl-deficient, amino acid-defined diets. Carcinogenesis $13,1869-1872$. 